\title{
H3N2 canine influenza virus causes severe morbidity in dogs with induction of genes related to inflammation and apoptosis
}

\author{
Young Myong Kang ${ }^{1,2+}$, Heui Man Kim ${ }^{1,2+}$, Keun Bon Ku ${ }^{1,2}$, Eun Hye Park ${ }^{1,2}$, Jung Yum ${ }^{1,2}$ and Sang Heui Seo ${ }^{1,2^{*}}$
}

\begin{abstract}
Dogs are companion animals that live in close proximity with humans. Canine H3N2 influenza virus has been isolated from pet dogs that showed severe respiratory signs and other clinical symptoms such as fever, reduced body weight, and interstitial pneumonia. The canine H3N2 influenza virus can be highly transmissible among dogs via aerosols. When we analyzed global gene expression in the lungs of infected dogs, the genes associated with the immune response and cell death were greatly elevated. Taken together, our results suggest that canine H3N2 influenza virus can be easily transmitted among dogs, and that severe pneumonia in the infected dogs may be partially due to the elevated expression of genes related to inflammation and apoptosis.
\end{abstract}

\section{Introduction}

The influenza virus infecting vertebrates is categorized as genera $\mathrm{A}, \mathrm{B}$, and $\mathrm{C}$ on the basis of the antigenic differences in their nucleoprotein (NP) and matrix proteins $(\mathrm{M})[1,2]$. Influenza A virus is further categorized according to the 16 subtypes of hemagglutinin (HA) and 9 subtypes of neuraminidase (NA) [2,3]. All the known influenza A viruses can be found in aquatic birds, and have a broad spectrum of hosts, including chickens, cats, dogs, pigs, whales, and humans [2]. The transmission of influenza from animals to humans does not give rise systemically to a pandemic. It is predicted that pandemics caused by influenza A virus may occur 3-4 times per century. During the $20^{\text {th }}$ century, humans experienced three pandemics: an H1N1 pandemic in 1918, an H2N2 pandemic in 1957, and an H3N2 pandemic in 1968 [4-9]. The first pandemic of the 21st century occurred in 2009, caused by the swine-originated H1N1 influenza virus [10].

Dogs are one of the most popular companion animals and live in close contact with humans. Dogs infected with influenza A viruses, including H3N8, H3N2, and

\footnotetext{
*Correspondence: seos@cnu.ac.kr

${ }^{\dagger}$ Equal contributors

'Laboratory of Influenza Research, College of Veterinary Medicine, Chungnam National University, Daejeon, South Korea

${ }^{2}$ Institute for Influenza Virus, College of Veterinary Medicine, Chungnam National University, Daejeon, South Korea
}

H5N1, have been previously reported [11-13]. An H3N8 influenza A virus was isolated in January 2004 from the lung tissues of racing greyhound dogs that suffered from severe clinical signs such as high fever, hemorrhagic tracheitis, bronchopneumonia, and vasculitis [11,14]. Further cases of $\mathrm{H} 3 \mathrm{~N} 8$ infections in racing dogs were reported in 6 US states in the summer of 2004, and in 11 US states in 2005 and 2006 [11,14,15]. More H3N8 influenza viruses were isolated from archived tissues of greyhound dogs that died in Florida in late 2003, from greyhound dogs in Texas in 2004, and from 2 pet dogs in 2005 [14]. Fatally infected dogs that had fed on the carcasses of chickens infected with highly pathogenic (HP) H5N1 influenza virus were reported in Thailand [12]. Serological study of 629 village dogs for H5 antibodies in central Thailand showed that some of those dogs were positive for H5N1 infection [16]. These studies were conducted to evaluate dogs as potential vectors in the transmission of HP H5N1 influenza virus to humans $[17,18]$. The studies showed that dogs inoculated with the HP H5N1 influenza virus did not show severe clinical signs, but suffered only from conjunctivitis and showed transiently elevated body temperature. All inoculated dogs were seroconverted, and transmission of viruses from inoculated dogs to contact dogs was not observed. An outbreak of avian origin H3N2 influenza virus in pet dogs occurred in South Korea in 2007 [13]. 
When beagles were infected with the canine H3N2 influenza virus, they suffered from high fever, necrotizing tracheobronchitis, and bronchioalveolitis [13]. Avian origin $\mathrm{H} 3 \mathrm{~N} 2$ influenza virus was also isolated from clinically ill dogs in southern China in 2006 and 2007 [19].

In this study, we are interested in finding out the pathogenicity of a recently isolated canine H3N2 influenza virus in dogs. Therefore, we examined the clinical signs of dogs infected with a canine H3N2 influenza virus and the morphology of a recently isolated, avian origin, canine H3N2 influenza virus. We used broadspectrum microarray analysis and real-time PCR to investigate the possible pathogenesis by which the H3N2 influenza virus infected the dogs.

\section{Materials and methods \\ Virus}

A canine influenza virus, A/Korea/S1/Canine/2012 (H3N2), was isolated from a dog showing respiratory clinical signs in an animal clinic in Korea in 2012 using a nasal swab in PBS (pH 7.4) to inoculate a 10-day-old hen egg.

\begin{abstract}
Animals
Approximately 2-month-old Korean farm dogs (Korean mongrel, $n=3$ ) were serologically tested using a hemagglutination-inhibition (HI) assay with $0.5 \%$ turkey red blood cells. They were negative for human influenza viruses (H1N1, H3N2, and Influenza virus B) and canine H3N2 influenza virus. All animal experiments were performed at a biosafety level 3 (BSL-3) facility approved by the Korean government.
\end{abstract}

\section{Ethics statement}

This study was carried out in strict accordance with the recommendations in the Guide for the Care and Use of Laboratory animals of Korean veterinary quarantine and service. The animal experiments were approved by the Animal Experimental Ethics Committee at the Chungnam National University.

\section{Canine H3N2 influenza virus imaging by transmission electron microscopy}

The H3N2 canine influenza virus was propagated in a 10-day-old hen at $35{ }^{\circ} \mathrm{C}$ for $60 \mathrm{~h}$. The allantoic fluid containing the virus was harvested and concentrated to one-tenth of the original volume using an Amicon concentrator apparatus. The concentrated viruses were purified using a $20-75 \%$ sucrose continuous gradient at 26 $000 \mathrm{rpm}\left(4^{\circ} \mathrm{C}\right)$ for $2 \mathrm{~h}$. The purified viruses were fixed in a $2.5 \%$ paraformaldehyde-glutaraldehyde mixture buffered with $0.1 \mathrm{M}$ phosphate ( $\mathrm{pH} \mathrm{7.2)} \mathrm{for} 2 \mathrm{~h}$, postfixed in $1 \%$ osmium tetroxide in the same buffer for $1 \mathrm{~h}$, dehydrated in graded ethanol and propylene oxide, and embedded in Epon-812. The sample was stained with uranyl acetate and lead citrate, and examined under a CM 20 (Philips, Netherlands) electron microscope.

\section{Measurement of clinical signs and viral titers in infected dogs}

The dogs $(n=3)$ were infected intranasally (i.n.) with $10^{6}$ EID $_{50}$ of canine H3N2 influenza virus, and the rectal body temperature and body weight were measured for 14 days after infection. Daily swabs were obtained from the trachea and rectum, suspended in PBS ( $\mathrm{pH} 7.4$ ), and used to inoculate a 10-day-old hen egg to determine the $\log _{10}$ egg infectious dose $50 / \mathrm{mL}\left(\log _{10} \mathrm{EID}_{50} / \mathrm{mL}\right)$. The $\mathrm{EID}_{50} / \mathrm{mL}$ was calculated as previously described [20]. Three other Korean mongrels were mock-infected with PBS as controls.

\section{Clinical scores of infected dogs}

Clinical signs were observed in the dogs for 14 days after infection. The clinical scores were the mean score of activity and respiratory signs. Ocular and nasal discharges were scored as follows: 0 for no discharge, 1.0 for serous discharge, 2.0 for mild mucus, and 3.0 for copious mucus. Cough was scored as 0 for no cough, 1.0 for mild cough, 2.0 for moderate or persistent cough, and 3.0 for severe cough accompanied by choking or retching sounds. Their appetite was scored as 0 for present, 1.0 for mild anorexia, 2.0 for mild anorexia and adipsia, and 3.0 for persistent anorexia and depression. Their hair was scored as 0 for normal, 1.0 for mildly rough, 2.0 for moderately rough, and 3.0 for severely rough hair.

\section{Aerosol transmission of canine H3N2 influenza virus in dogs}

Aerosol transmission of canine H3N2 influenza virus was performed as described in reference [21]. The 3 experimental dogs infected with $10^{6}$ p.f.u. of canine H3N2 influenza virus were placed in a cage, and 1 day later, 3 naïve dogs in the cage were placed about $90.0 \mathrm{~cm}$ apart from the experimental dogs. The nasal and cloacal swabs in PBS ( $\mathrm{pH} 7.4$ ) were acquired 3 and 5 days after the transmission setup. The viral titers in swabs were determined by $\mathrm{EID}_{50} / \mathrm{mL}$.

\section{Imaging of gross lung lesions}

The experimentally-infected dogs were euthanized at day 5 post infection using intravenous injection of T61 $(0.3 \mathrm{~mL} / \mathrm{kg}$ of body weight; Intervet, USA). Lung tissues (left cranial lobes) were then collected. The lung tissues of the control dogs were also acquired in a similar manner. Images of the ventral and dorsal lesions of lungs were captured. 


\section{Histopathological staining and immunohistochemistry of lung tissues}

The lung tissues were fixed by immersing in $10 \%$ neutral buffered formalin, and were embedded in paraffin. Fivemicrometer-thick sections were made from the paraffinembedded tissues, and were stained with hematoxylin and eosin (H\&E) as described previously [22]. The stained tissues were evaluated under an Olympus DP70 microscope (Olympus Corporation, Tokyo, Japan).

Five-micrometer-thick sections were stained with mouse anti-influenza A virus nucleoprotein antibody (Serotech, United Kingdom) [23]. The tissue sections were deparaffinized and hydrated in distilled water, followed by fixing with $100 \%$ chilled acetone for $2 \mathrm{~h}$ for permeabilization. The endogenous peroxidase activity was blocked by incubating the sections in $3 \% \mathrm{H}_{2} \mathrm{O}_{2}$ for $15 \mathrm{~min}$ at $37{ }^{\circ} \mathrm{C}$ before the sections were blocked with $5 \%$ bovine serum albumin in PBS ( $\mathrm{pH} 7.4)$ for $1 \mathrm{~h}$. The blocked tissue sections were labeled with mouse antiinfluenza A virus nucleoprotein antibody (1:1000 dilution) by incubating at room temperature for $1 \mathrm{~h}$. The labeled tissue sections were stained with biotin-labeled goat anti-mouse immunoglobulin (Vector, USA), VECTASTAIN ABC-AP (Vector, USA), and Vector red alkaline phosphatase substrate (Vector, USA). The stained tissue sections were counterstained with hematoxylin QS (Vector Laboratories, Burlingame, CA, USA), after which the stained sections were evaluated under an Olympus DP70 microscope (Olympus Corporation, Tokyo, Japan).

\section{Gene expression and transcription analysis using DNA microarray in the dog lung tissues}

Sterile mortars and pestles were used to pulverize about $1 \mathrm{~g}$ of each lung tissue sample in liquid nitrogen; the samples were crushed until a fine powder remained. The powder from each sample was placed into a cold 2-mL microtube, and $1000 \mu \mathrm{L}$ of TRIzol (Invitrogen, USA) was added and mixed by inverting the tube to help in cell lysis. The TRIzol solution containing the disrupted tissue was then centrifuged at $12000 \mathrm{~g}$ for $10 \mathrm{~min}$ at $4{ }^{\circ} \mathrm{C}$. The colorless supernatant phase was collected into a new 2-mL tube and incubated in ice for $5 \mathrm{~min}$, after which $200 \mu \mathrm{L}$ of chloroform (Sigma-Aldrich, USA) was added to the samples, vigorously shaken by hand, and incubated again in ice for $2 \mathrm{~min}$. This solution was centrifuged at $12000 \mathrm{~g}$ for $15 \mathrm{~min}$ at $4{ }^{\circ} \mathrm{C}$, and the aqueous phase was collected into a new cold tube. Chilled isopropyl alcohol (500 $\mu \mathrm{L}$; Sigma-Aldrich, USA) was added to the solution for RNA separation, mixed by inverting the tube, and incubated in ice for $10 \mathrm{~min}$. The solution was centrifuged at $12000 \mathrm{~g}$ for $10 \mathrm{~min}$ at $4{ }^{\circ} \mathrm{C}$, after which the supernatant was decanted, and the pellet, recovered. Then, the RNA pellet was washed with $1000 \mu \mathrm{L}$ of $75 \%$ chilled ethanol (Sigma-Aldrich, USA), and the tube was inverted to wash the RNA. The solution was centrifuged at $9000 \mathrm{~g}$ for $5 \mathrm{~min}$ at $4{ }^{\circ} \mathrm{C}$. The supernatant was then decanted, the pellet was recovered, and was air-dried at room temperature for approximately $10-15 \mathrm{~min}$. RNA was dissolved into $50 \mu \mathrm{L}$ of DEPC-treated water by pipetting the solution a few times and treated with DNase (Qiagen, USA).

The synthesis of target cRNA probes and hybridization were performed on equal amounts of control and test RNA from each dog using Agilent's Low RNA Input Linear Amplification kit (Agilent Technology, USA) according to the manufacturer's instructions. For each sample, $1 \mathrm{~g}$ of total RNA and T7 promoter primer mix was incubated at $65{ }^{\circ} \mathrm{C}$ for $10 \mathrm{~min}$. A cDNA master mix (5x First strand buffer, 0.1 M DTT, $10 \mathrm{mM}$ dNTP mix, RNase-Out, and MMLV-RT) was prepared and added to the reaction mix. The samples were incubated at $40{ }^{\circ} \mathrm{C}$ for $2 \mathrm{~h}$ and then at room temperature; the dsDNA synthesis was terminated by incubating at $65{ }^{\circ} \mathrm{C}$ for $15 \mathrm{~min}$. The transcription master mix was prepared according to the manufacturer's protocol $(4 \times$ Transcription buffer, 0.1 M DTT, NTP mix, 50\% PEG, RNase-Out, inorganic pyrophosphatase, T7-RNA polymerase, and Cyanine 3CTP). Transcription of the dsDNA was achieved by adding the transcription master mix to the dsDNA reaction samples, and incubating at $40{ }^{\circ} \mathrm{C}$ for $2 \mathrm{~h}$. Amplified and labeled cRNA was purified on a cRNA Cleanup Module (Agilent Technology) according to the manufacturer's protocol. Labeled cRNA target was quantified using an ND-1000 spectrophotometer (NanoDrop Technologies, Inc., Wilmington, DE, USA). After checking labeling efficiency, fragmentation of cRNA was performed by

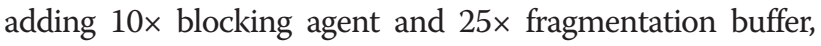
and incubating at $60{ }^{\circ} \mathrm{C}$ for $30 \mathrm{~min}$. The fragmented cRNA was resuspended in $2 \times$ hybridization buffer and directly pipetted onto an assembled Agilent Canine Oligo Microarray (44 K) [24]. The arrays were hybridized at $65{ }^{\circ} \mathrm{C}$ for $17 \mathrm{~h}$ using an Agilent Hybridization oven (Agilent Technology, USA). The hybridized microarrays were washed according to the manufacturer's washing protocol (Agilent Technology, USA).

The hybridized images were scanned using Agilent's DNA microarray scanner and quantified with Feature Extraction Software (Agilent Technology, Palo Alto, CA, USA). All data normalization and selection of fold changes in gene expression were carried out using GeneSpringGX 7.3 (Agilent Technology, USA). The averages of normalized ratios were calculated by dividing the average of normalized signal channel intensity by the average of normalized control channel intensity. Functional annotation of genes was performed according to the Gene Ontology database [25], BioCarta [26], GenMAP [27], DAVID bioinformatics resource [28], and 
Table 1 Real-time PCR primer sequences

\begin{tabular}{|c|c|c|c|}
\hline \multirow[t]{2}{*}{ Group } & Gene & Forward primer & Reverse primer \\
\hline & GAPDH & TCA ACG GAT TTG GCC GTA TTG G & TGA AGG GGT CAT TGA TGG CG \\
\hline TLR & TLR2 & TGT TGT TGG GCA ACT GAA AA & TTA AAC AAG TGG GGC AAA GG \\
\hline \multirow[t]{2}{*}{ NK cell } & IL15 & AGT AAC CGC GAT GAA GTG CT & CTT TGC ATC CCG TTT CAG TT \\
\hline & FCIGR & CCT GGT GAT GGC ACT CCT AT & GGG TTG TGG ATC CAG AGA GA \\
\hline \multirow[t]{2}{*}{ Macrophage } & MARCO & CCA GGA CTT TTG GCC ATT TA & TTC TCT TCT TGG GCT TTG GA \\
\hline & MMP12 & GTC ACT GCT TCG GGT ACC AT & GAT GCA TCC AGT TTC CCA GT \\
\hline \multirow[t]{2}{*}{ Neutrophil } & CSF2 & AAC ATC CCC TTT GAC TGC TG & AAG TCC ATG CCC CCT CTA CT \\
\hline & SLPI & CCT TGG ACT GTG GAA GGT GT & ACC TGC CAG GCT TCA TTC TA \\
\hline \multirow[t]{4}{*}{$\mathrm{NO}$ and ROS } & GCLM & GGC GCA GGT AAA ACC AAA TA & GCT TTC CTG AAG GGC TTC TT \\
\hline & HSP90AA1 & GTC AGT GAC GAT GAG GCT GA & GTG ATG TCG TCA GGG TTC CT \\
\hline & ADM & CGA CGT CTC AGA CCT TCT CC & CCA CGA CTT ACA GCC CAT TT \\
\hline & SOD2 & TGT TGT TGG GCA ACT GAA AA & TTA AAC AAG TGG GGC AAA GG \\
\hline \multirow[t]{3}{*}{ IFN } & IFIT3 & TTC CCC ACA AGA GCA AAA TC & GCA GGA AAA AGC TGC CTA TG \\
\hline & ISG20 & CGA TGG AGC TTा ACC GAC TC & ATG CAT TTC CCA AAA GCA AG \\
\hline & $M \times 1$ & GGA GGC TCT GTC AGG AGT TG & TGA CTG ATC CCC TGT CCT TC \\
\hline \multirow[t]{5}{*}{ Cytokine and chemokine } & IL15 & AGT AAC CGC GAT GAA GTG CT & CTT TGC ATC CCG TTT CAG TT \\
\hline & C3 & CGC TAC CAG AAC CTG AGG AG & CGG ACG ACA GGA GGT ACA TT \\
\hline & IL10RB & GCC TTC ACG GAA TGT GAT TT & TAG GGG CTA AGA AAC GCA GA \\
\hline & IL1R2 & ATG GGT GTT TCA GCC TTC AC & CTG GAC CCA CAT TCT CGT CT \\
\hline & CXCL10 & TGA ACC AAA GTG CTG TTC TTA TाT & ACG ATG GAC TTG CAG GAA TC \\
\hline \multirow[t]{2}{*}{ DC } & TAP1 & CCA TGG CTC TCA CTA GCA CA & GCA GGC TGG AGC TCA ATT AC \\
\hline & $M \times 1$ & GGA GGC TCT GTC AGG AGT TG & TGA CTG ATC CCC TGT CCT TC \\
\hline \multirow[t]{3}{*}{ Apoptosis } & TNFSF13 & GGG CGA AAC TTA GCC TCT CT & GGT TGA GGT CAA ACC CAG AA \\
\hline & NME5 & AAG GGC AAT TTA TGG CAC AG & CCG CTG GTT TCT CCT TAC AA \\
\hline & PYCARD & CTG CAG GAG ACC TCA CAC AA & TCC TCA TTT TCC CTG GAT TG \\
\hline $\mathrm{TH} 1$ & SPP1 & TTG CAG TGA TाT GCT TाT GC & CAG ACT CGT TGG AGT CGT CA \\
\hline \multirow[t]{2}{*}{$\mathrm{TH} 2$} & CCL5 & GCT GCT TTG CCT ACA TIT CC & TCA GGT TCC AGA TGC CCT AC \\
\hline & CCL7 & CCC ATC CAG AAG CTG AAG AG & GCT TGG GTT TTC TTG TCC AG \\
\hline
\end{tabular}

National center for biotechnology information [29]. GEO accession number is GSE44545.

\section{Quantification of dogs' genes by real-time polymerase chain reaction $(P C R)$}

Total RNA was collected from lung tissues ( $1 \mathrm{~g})$ of dogs ( $n=3$ per group) that were infected with canine H3N2 influenza virus using TRIzol reagent (Invitrogen, Carlsbad, CA, USA). One milliliter of TRIzol reagent (Invitrogen) was added to tubes containing tissues and incubated at room temperature for $5 \mathrm{~min}$. Chloroform (200 L) was added and the solution was mixed by vortexing for $15 \mathrm{~s}$ and centrifuged for $15 \mathrm{~min}$ (12 $000 \mathrm{rpm}, 4{ }^{\circ} \mathrm{C}$ ). The upper RNA-containing band was collected and mixed with $500 \mathrm{~L}$ of isopropanol (Sigma-

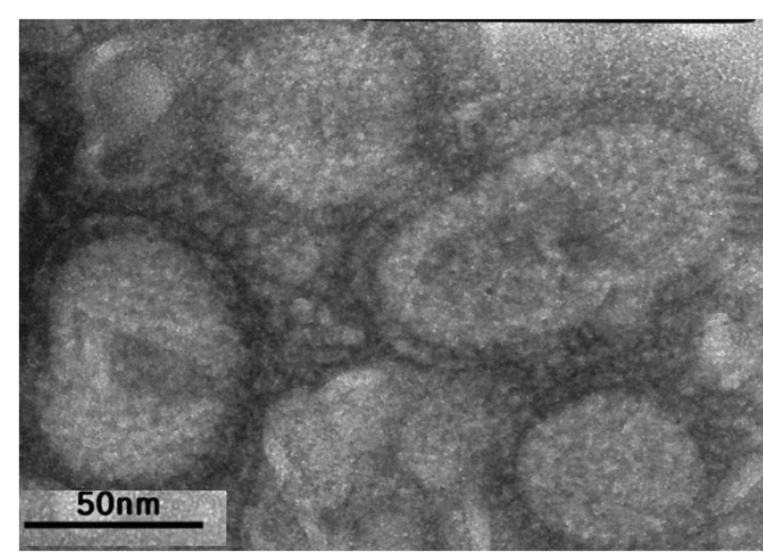

Figure 1 Morphology of the canine H3N2 influenza virus. H3N2 canine influenza virus (A/Korea/S1/Canine/2012) propagated in eggs was purified by sucrose gradient centrifugation. The purified virion was observed using a transmission electron microscope. 


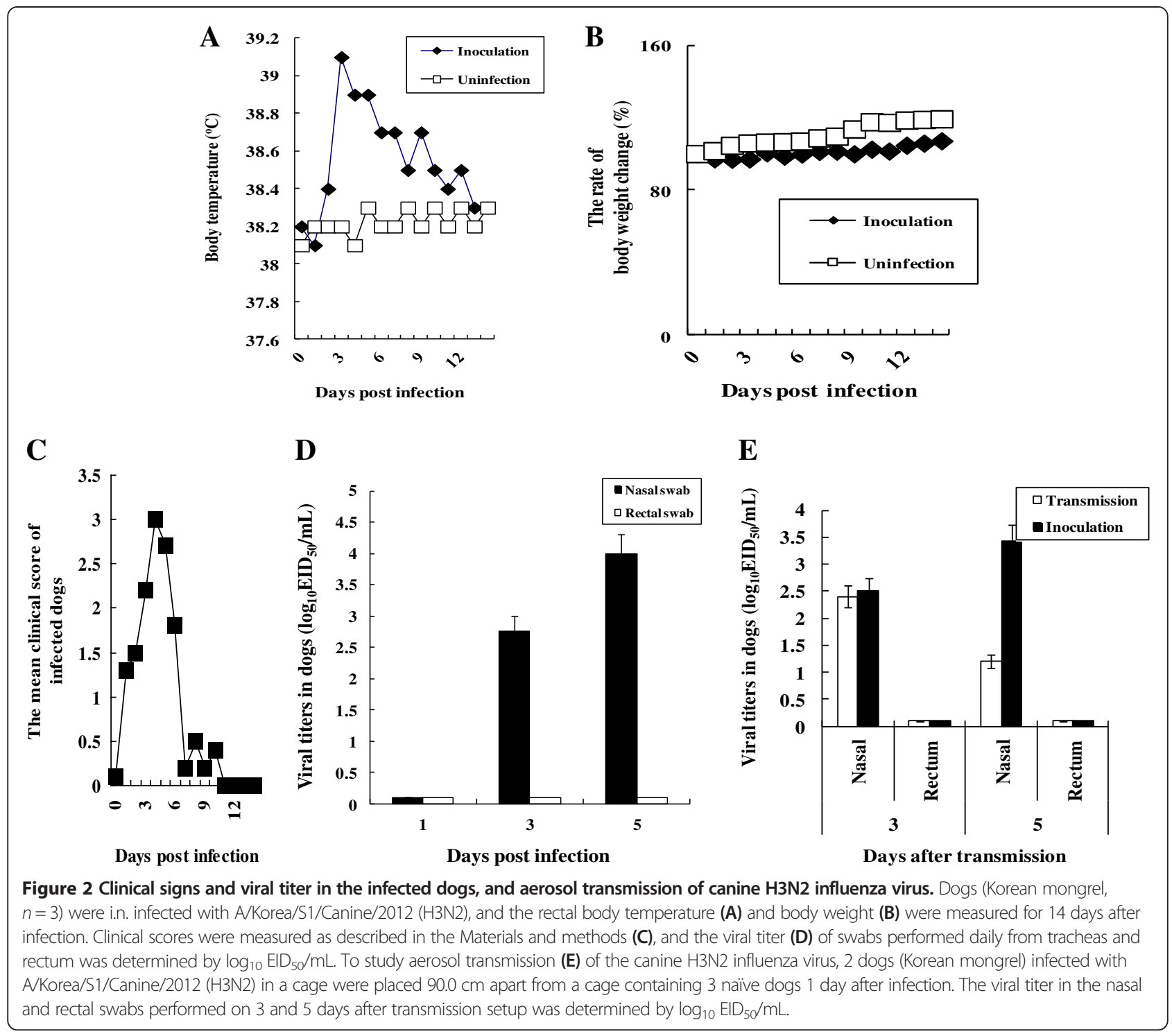

Aldrich, St. Louis, MO, USA) in a new $1.5 \mathrm{~mL}$ tube. Each sample was centrifuged for $10 \mathrm{~min}(10000 \mathrm{rpm}$, $4{ }^{\circ} \mathrm{C}$ ), and the RNA-containing pellet was washed with $100 \mu \mathrm{L}$ of $75 \%$ ethanol in water by centrifuging for $5 \mathrm{~min}\left(10000 \mathrm{rpm}\right.$ and $\left.4{ }^{\circ} \mathrm{C}\right)$. The washed RNA was resuspended in $50 \mu \mathrm{L}$ of diethyl pyrocarbonate (DEPC)treated water.

The mRNA of dogs' inflammatory cytokines and chemokines were quantified using quantitative realtime PCR. To synthesize the cDNA, $1 \mu \mathrm{L}$ of oligo dT primers (0.5 pmoles) (Promega, Madison, WI, USA) was added to a total volume of $9 \mu \mathrm{L}$ in a $0.05 \mathrm{~mL}$ tube. The mixture was reacted for $5 \mathrm{~min}$ at $70{ }^{\circ} \mathrm{C}$ prior to incubation for $5 \mathrm{~min}$ at $4{ }^{\circ} \mathrm{C}$. Then, each sample received $4 \mu \mathrm{L}$ of $25 \mathrm{mM} \mathrm{MgCl}_{2}, 4 \mu \mathrm{L}$ of $5 \mathrm{X}$ reverse transcriptase enzyme buffer, $1 \mu \mathrm{L}$ of RNase inhibitor, $1 \mu \mathrm{L}$ of reverse transcriptase, and $1 \mu \mathrm{L}$ of dNTP $(10 \mathrm{mM})$. Each sample was incubated for $5 \mathrm{~min}$ at $25{ }^{\circ} \mathrm{C}$, for $60 \mathrm{~min}$ at $42{ }^{\circ} \mathrm{C}$, and $15 \mathrm{~min}$ at $70{ }^{\circ} \mathrm{C}$. SYBR Green-based real-time PCR was performed using a Roto-Gene 6000 apparatus (Corbett, Mortlake, Australia) and SensiMix Plus SYBR (Quantace, London, UK) based on recommendations of the manufacturer. A duplicate of each sample was run. A total volume of $20 \mu \mathrm{L}$ containing $2 \mu \mathrm{L}$ cDNA, $10 \mu \mathrm{L}$ SYBR mixture, and gene-specific primers (Table 1) $(1 \mu \mathrm{L}$ of forward primer $(20$ pmole $)$ and $1 \mu \mathrm{L}$ of reverse primer (20 pmole)) was used for 40 cycles of PCR: $5 \mathrm{~s}$ at $95{ }^{\circ} \mathrm{C}, 15 \mathrm{~s}$ at $60{ }^{\circ} \mathrm{C}$, and $25 \mathrm{~s}$ at $72{ }^{\circ} \mathrm{C}$. Cytokine and TLR expression levels in tissues were normalized to those of dog glyceraldehyde-3-phosphate dehydrogenase (GAPDH). The results of realtime PCR were quantified by the comparative threshold method after deductions of data from uninfected control dogs. 


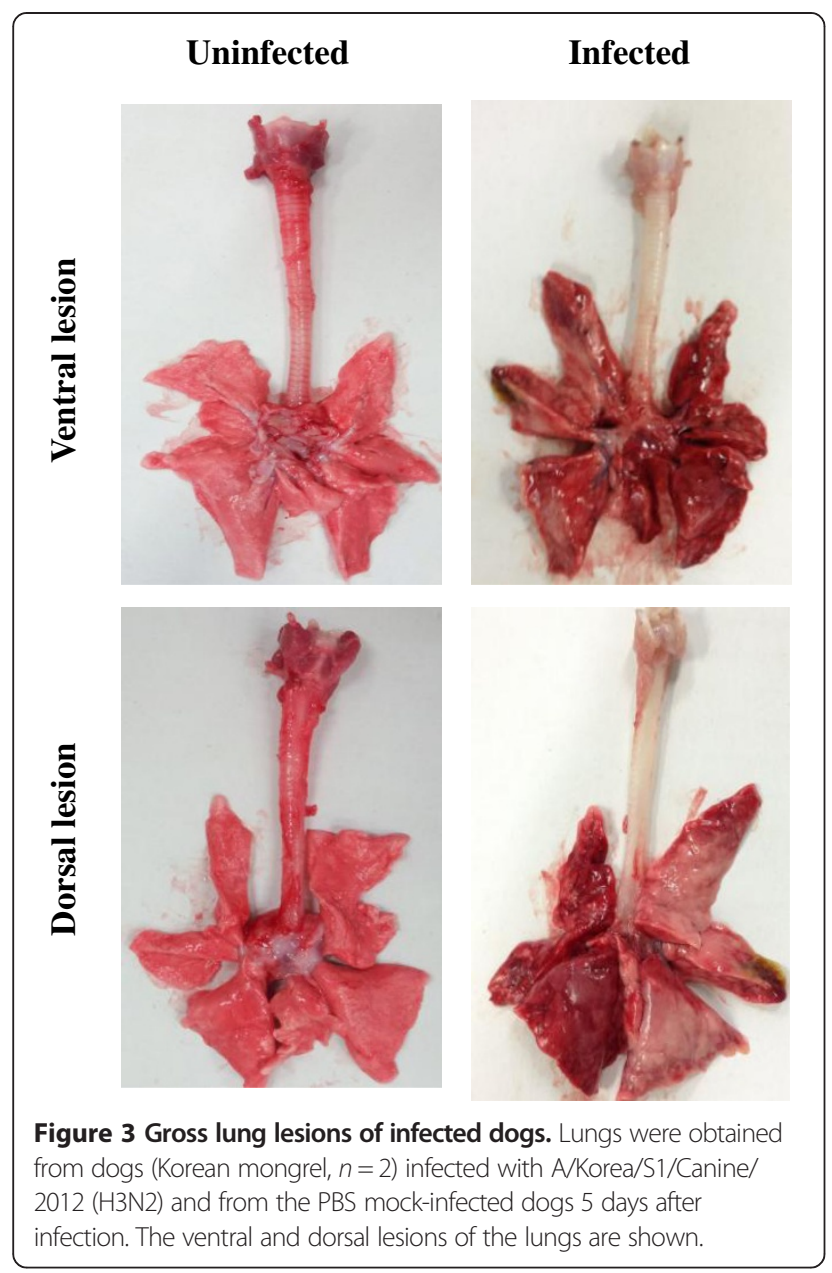

\section{Statistical analysis}

Statistical analysis was performed using the Statistical Product and Services Solutions (SPSS) package, version 10.0 (SPSS, Cary, NC, USA). Student's $t$-test was used. A $P$-value $<0.05$ was considered to be statistically significant. The data from the infected dogs were compared with those from the uninfected dogs.

\section{Results}

\section{Morphology of isolated canine H3N2 influenza virus}

To determine the shape of avian origin canine H3N2 influenza virus, the purified virus was observed by transmission electron microscopy. The image shows that the virion contains an envelope and surface projections, and that the shape is pleomorphic, which is typical of enveloped viruses (Figure 1).

\section{Clinical signs, viral titers, and aerosol transmission of canine H3N2 influenza virus in dogs}

When the dogs were i.n. inoculated with H3N2, they suffered from elevated body temperature and reduced body weight, and shed the virus via the upper respiratory tract (Figure 2A-D). The rectal body temperature in the infected dogs peaked at $39.1{ }^{\circ} \mathrm{C} 3$ days after infection (Figure 2A), and the body weight of the infected dogs decreased to $98.6 \%$ of that prior to the infection (Figure 2B). The overall clinical score peaked at 3.0 on 4 days after infection (Figure 2C). When we measured viral titers from the nasal and rectal swabs of the infected dogs, viruses were only detected in the nasal swabs with 4.0 $\mathrm{EID}_{50} / \mathrm{mL} 5$ days after infection (Figure 2D).

We tested the possibility of aerosol transmission of canine H3N2 influenza virus among dogs to determine whether the avian origin canine $\mathrm{H} 3 \mathrm{~N} 2$ influenza virus is well adapted in dogs. When the cage containing the infected dogs was placed $90.0 \mathrm{~cm}$ apart from the cage containing naïve dogs, the viruses were detected in the nasal swabs of the naïve dogs 3 and 5 days after transmission (Figure 2E), suggesting that canine H3N2 influenza virus has an effective transmission among dogs via aerosols.

\section{Gross pathology, histopathology, and immunohistochemistry of the lungs of infected dogs}

We compared the gross pathological lesions of the lungs of the infected and uninfected dogs. The left cranial, middle, and caudal lobes of infected lungs had severe pneumonia, along with edema and hemorrhage (Figure 3). The H\&E staining of the tissues showed interstitial pneumonia with infiltration of numerous inflammatory cells (Figure 4B). Lung tissues stained with the antibody against influenza A nucleoprotein were positive mainly in the pneumocytes with some alveolar macrophages (Figure 4D).

\section{Analysis of gene transcription induced in the lungs of infected dogs}

We performed a microarray analysis of mRNA collected from the lungs of canine H3N2 influenza virus-infected and PBS mock-infected dogs to understand the underlying mechanism by which the virus could cause severe respiratory signs. Many genes related to innate immunity were induced, such as Toll-like receptors (TLR), natural killer (NK) cells, macrophages, neutrophils, nitric oxide (NO) molecules and reactive oxygen species (ROS), interferons (IFN), and cytokines and chemokines (Figures 5 and 6). Among TLR 1-10, TLR2 recognizes foreign substances and transmits appropriate signals to the immune cells, and it had the greatest induction (19.5-fold increase, Figure $5 \mathrm{E}$ ). When we quantified mRNA of TLR2 by real-time PCR, the induction of TLR2 increased as much as 21.3 fold compared to the uninfected control (Figure 5F). The greatest inductions (an 854.0-fold increase) in gene expression in NK cells were also seen with that for the Fc fragment of IgG (FClGR, low affinity IIIa, receptor), which is involved in the removal of antigenantibody complexes from the circulation (Figure 5E). When 

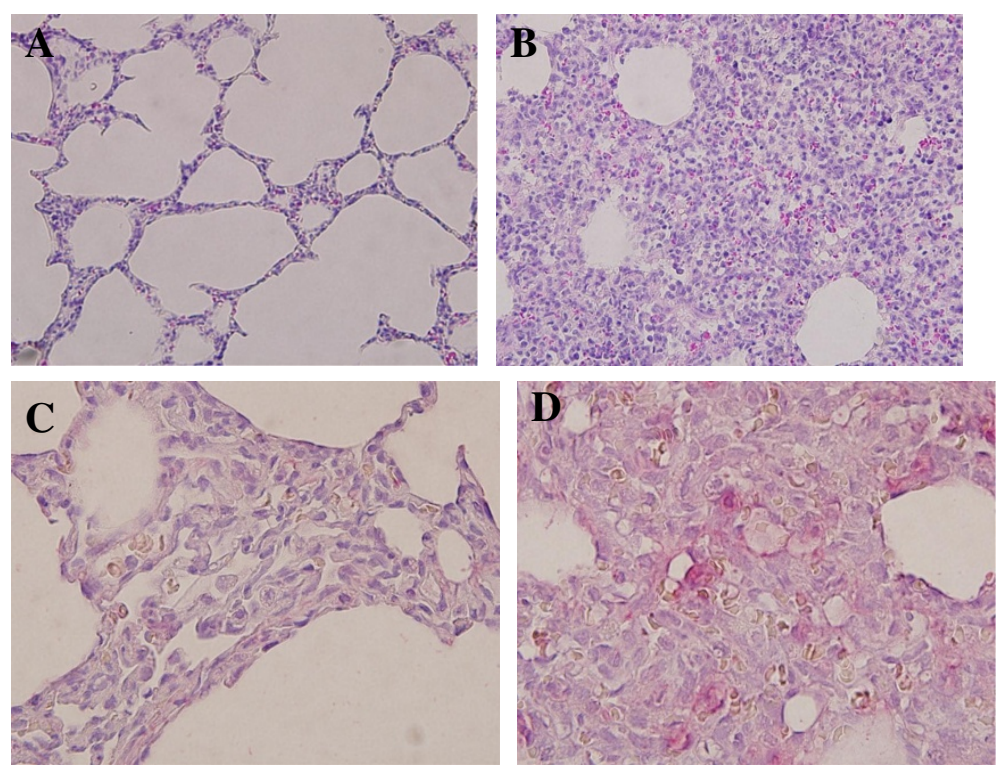

Figure 4 Histopathology and immunohistochemistry of the lungs of infected dogs. The left cranial lobes of the lungs from dogs (Korean mongrel, $n=2$ ) infected with A/Korea/S1/Canine/2012 (H3N2) and from PBS mock-infected dogs were collected 5 days after infection. The lung tissues from PBS mock-infected (A) or infected (B) dogs were stained with H\&E stain. In addition, the lung tissues from PBS mock-infected (C) or infected (D) dogs were stained with mouse anti-influenza A nucleoprotein antibody, biotin-labeled goat anti-mouse immunoglobulin, and red alkaline phosphatase substrate. The stained sections were imaged with an Olympus DP70 microscope.

mRNA of FCIGR was quantified with real-time PCR, its induction was a 560.0-fold increase (Figure 5F). Macrophage receptor with collagenous structure (MARCO), which is involved in the innate antimicrobial immune system, had a 127.3-fold increase among macrophages (Figure 5E). When mRNA of MARCO was quantified by real-time PCR, the induction of it was 94.3-fold increase (Figure 5F). Secretory leukocyte peptidase inhibitor (SLPI), which protects epithelial tissues from serine proteases, had a 109.9-fold increase among neutrophils (Figure 5E). When mRNA of SLPI was quantified by real-time PCR the induction of it was 167.1fold increase (Figure 5F). Among the NO- and ROS-related genes, the heat shock protein $90-\mathrm{kDa}$ alpha (Hsp90AA1) involved in the proper folding of specific target proteins had a 5725.6-fold increase (Figure 6D). When mRNA of Hsp90AA1 was quantified by real-time PCR the induction of it was a 3998.9-fold increase (Figure 6E). Superoxide dismutase 2 (SOD2) transforming toxic superoxides into hydrogen peroxide and diatomic oxygen had a 1080.5-fold increase (Figure 6D). When mRNA of SOD2 was quantified by real-time PCR the induction of it was a 931.9-fold increase (Figure 6E). Adrenomedullin (ADM), which increases the tolerance of cells to oxidative stress and hypoxic injury, had a 406.7-fold increase (Figure 6D). When mRNA of ADM was quantified by real-time PCR, the induction of it was a 477.3-fold increase (Figure 6E). Among the antiviral interferon-related genes, the most highly induced were myxovirus resistance 1 (Mx1), which is involved in a specific antiviral state against influenza virus infection, and had a 3878.0-fold increase (Figure 6D). When mRNA of $\mathrm{Mx} 1$ was quantified by real-time PCR, the induction of it was a 2990.8-fold increase (Figure 6E). Interferon stimulated exonuclease gene (ISG20), a $20-\mathrm{kDa}$ molecule, which degrades viral RNA, had an 890.0-fold increase (Figure 6D). When mRNA of ISG20 was quantified by real-time PCR, the induction of it was a 510.3 -fold increase (Figure 6E). The maximum induction among the cytokine and chemokine-related genes involved in inflammation was observed in chemokine (C-X-C motif) ligand 10 (CXCL10), which is associated with chemoattraction for monocytes, macrophages, $\mathrm{T}$ lymphocytes, NK cells, and dendritic cells, which showed a 381.0-fold increase (Figure 6D). When mRNA of CXCL10 was quantified by real-time PCR, the induction of it was a 227.2-fold increase (Figure 6E).

We also determined the expression of genes related to adaptive immunity and cell death such as those for dendritic cells, apoptosis, Th1 CD4 ${ }^{+}$lymphocytes, and Th2 $\mathrm{CD}^{+}$lymphocytes (Figure 7). Transporter 1 (TAP1), which transports various molecules across extra- and intracellular membranes, had a 7596.9-fold increase (Figure 7E) showing the greatest induction among genes related to dendritic cells and antigen presentation. When mRNA of TAP1 was quantified by real-time PCR the induction of it was 6271.1-fold increase (Figure 7F). Genes involved in cell death were also induced in the lungs of the infected dogs. Tumor necrosis factor superfamily 13 (TNFSF13), which induces apoptosis, had a 624.3-fold 


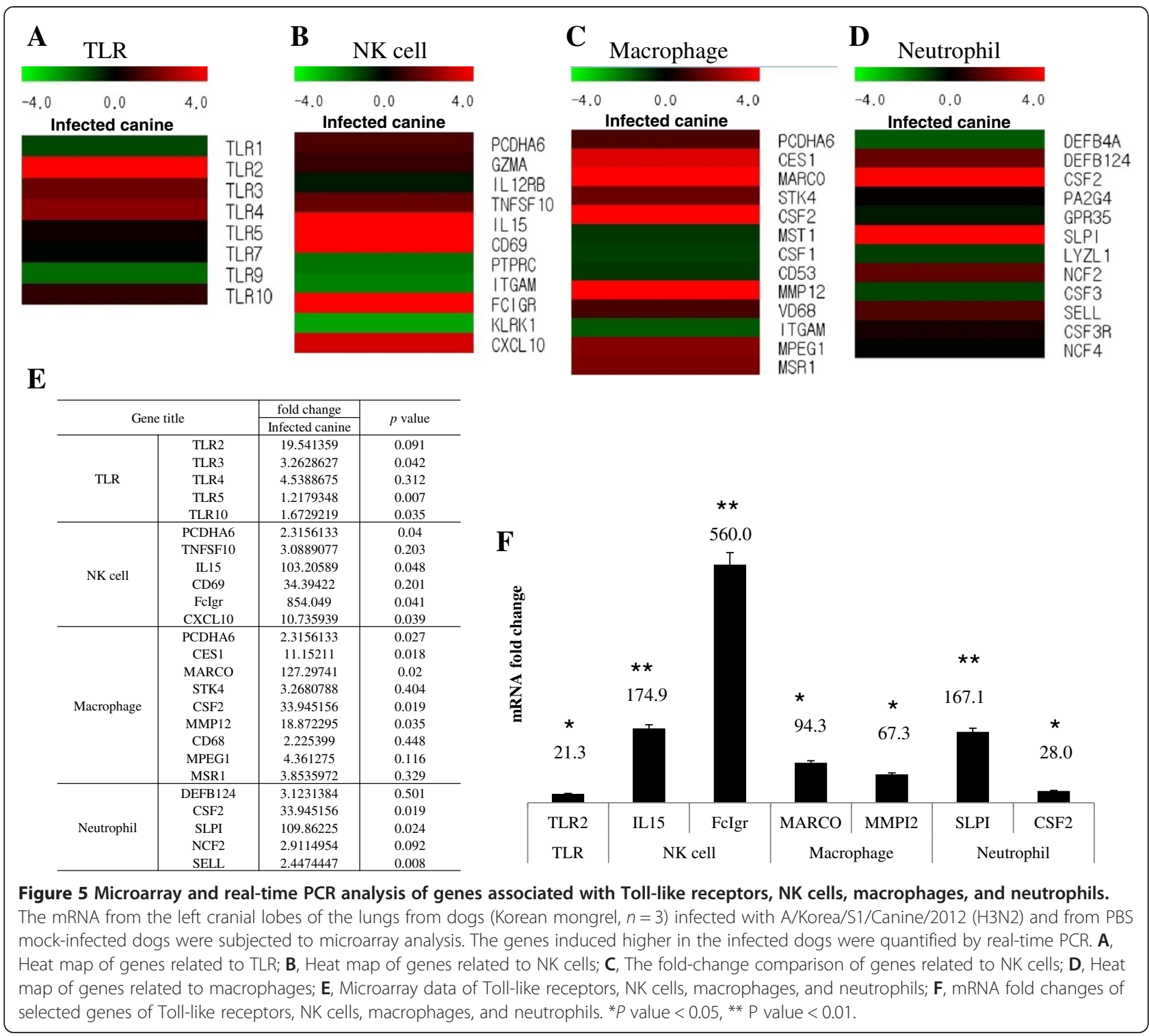

increase (Figure 7E). When mRNA of TNFSF13 was quantified by real-time PCR, the induction of it was 542.7-fold increase (Figure 7F). NME5 (non-metastatic cells 5), which alters the cellular levels of several antioxidant enzymes, had a 135.3-fold increase (Figure 7E). When mRNA of NME5 was quantified by real-time PCR the induction of it was a 185.7fold increase (Figure 7F). PYD and CARD domaincontaining (PYCARD), which mediates assembly of large signaling complexes in the inflammatory and apoptotic signaling pathways via the activation of caspase, had a 74.3-fold increase and was induced higher than any other apoptosis-related gene (Figure 7E). When mRNA of PYCARD was quantified by real-time PCR the induction of it was a 34.3-fold increase (Figure 7F). Secreted phosphoprotein 1 (SPP1) up-regulating the expression of IFN- $\gamma$ and IL-12 in Th1 CD4 $4^{+}$lymphocytes had a 46.7-fold increase (Figure 7E). When mRNA of SPP1 was quantified by real-time PCR, the induction of it was a 63.8-fold increase (Figure 7F). Chemokine (c-c motif) ligand 7 (CCL7), which attracts monocytes, had the highest induction at a 9.7-fold increase among Th2 $\mathrm{CD}^{+}{ }^{+}$lymphocytes (Figure 7E). When mRNA of CCL7 was quantified by real-time PCR, the induction of it was a 15.3-fold increase (Figure 7F). Ontology of gene expression showed that the infections of dogs with canine H3N2 influenza virus could induce a variety of genes involved in inflammation in lungs of infected dogs (Figure 8).

We think that the immune responses elicited in the dogs infected with canine H3N2 influenza virus may also contribute to the pathogenesis of influenza. 


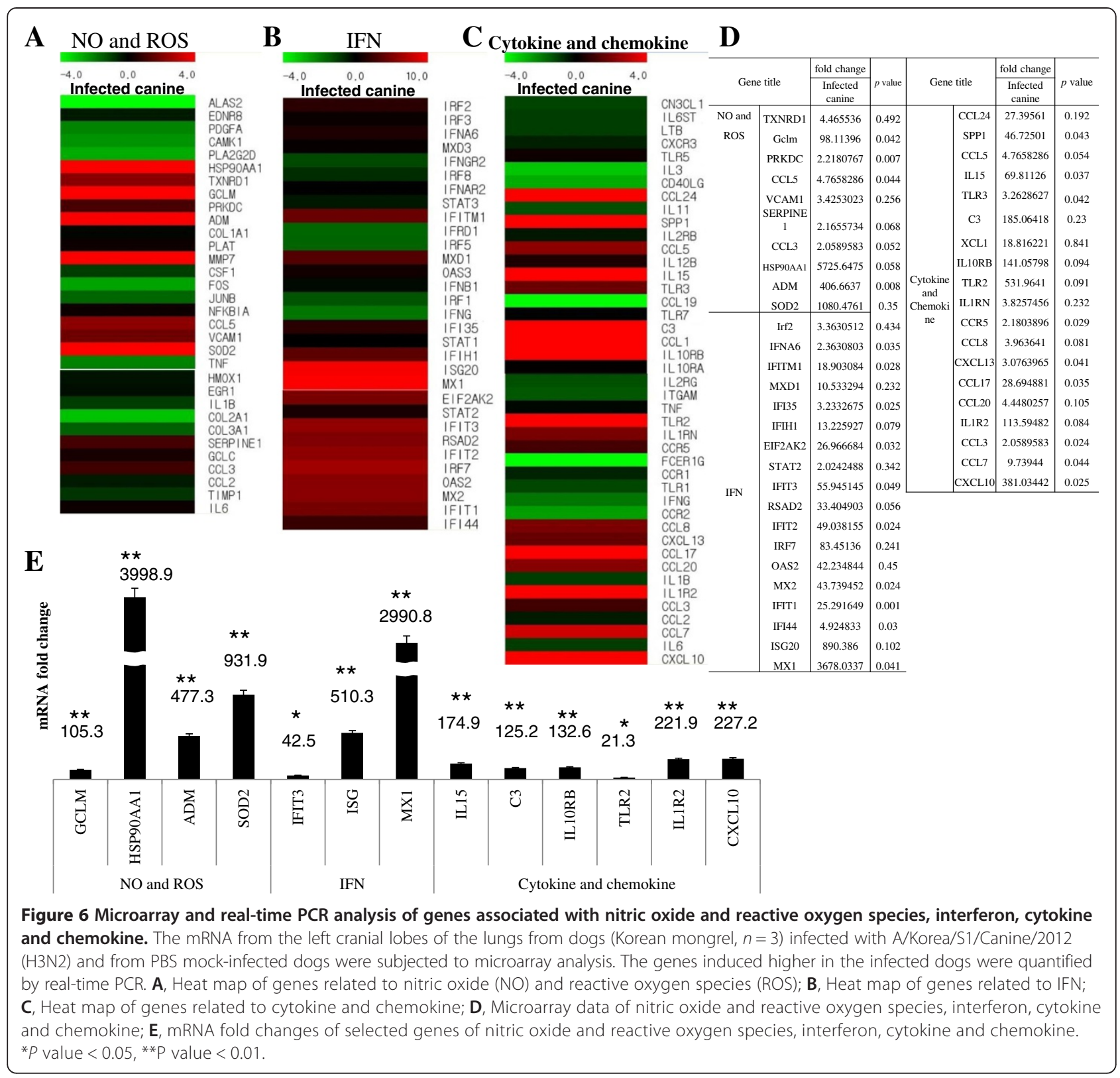

\section{Discussion}

Dogs live in close contact with humans. We characterized the pathogenicity of the avian origin H3N2 influenza virus in dogs. The infected dogs suffered from severe clinical signs, such as high fever, reduced body weight, and pneumonia. The canine H3N2 influenza virus could be efficiently transmitted via aerosols from the infected dogs to naïve dogs. Analysis of transcription induction in the lungs of infected dogs showed that a variety of genes related to innate and adaptive immunity and cell death were up-regulated.

Our data show that dogs infected with a recently isolated canine H3N2 influenza virus suffered from high fever and severe interstitial pneumonia. The previous study using 2007 canine H3N2 influenza virus also showed that the infected dogs suffered from high fever and the interstitial pneumonia and bronchioalveolitis [13].

Our results suggest that a canine H3N2 influenza virus is well adapted in dogs since this virus could efficiently transmit itself through aerosols. The aerosol transmission studies were performed to evaluate the potential transmission of influenza virus among humans using an animal model [30-34]. The transmission efficiency of avian origin $\mathrm{H} 5 \mathrm{~N} 1$ influenza virus in ferrets has been previously studied [30,31]. The reassortant H5HA/H1N1 virus containing $\mathrm{H} 5 \mathrm{HA}$ with four mutations and the remaining 7 genes from the 2009 pandemic H1N1 influenza virus could transmit among ferrets via droplets, 


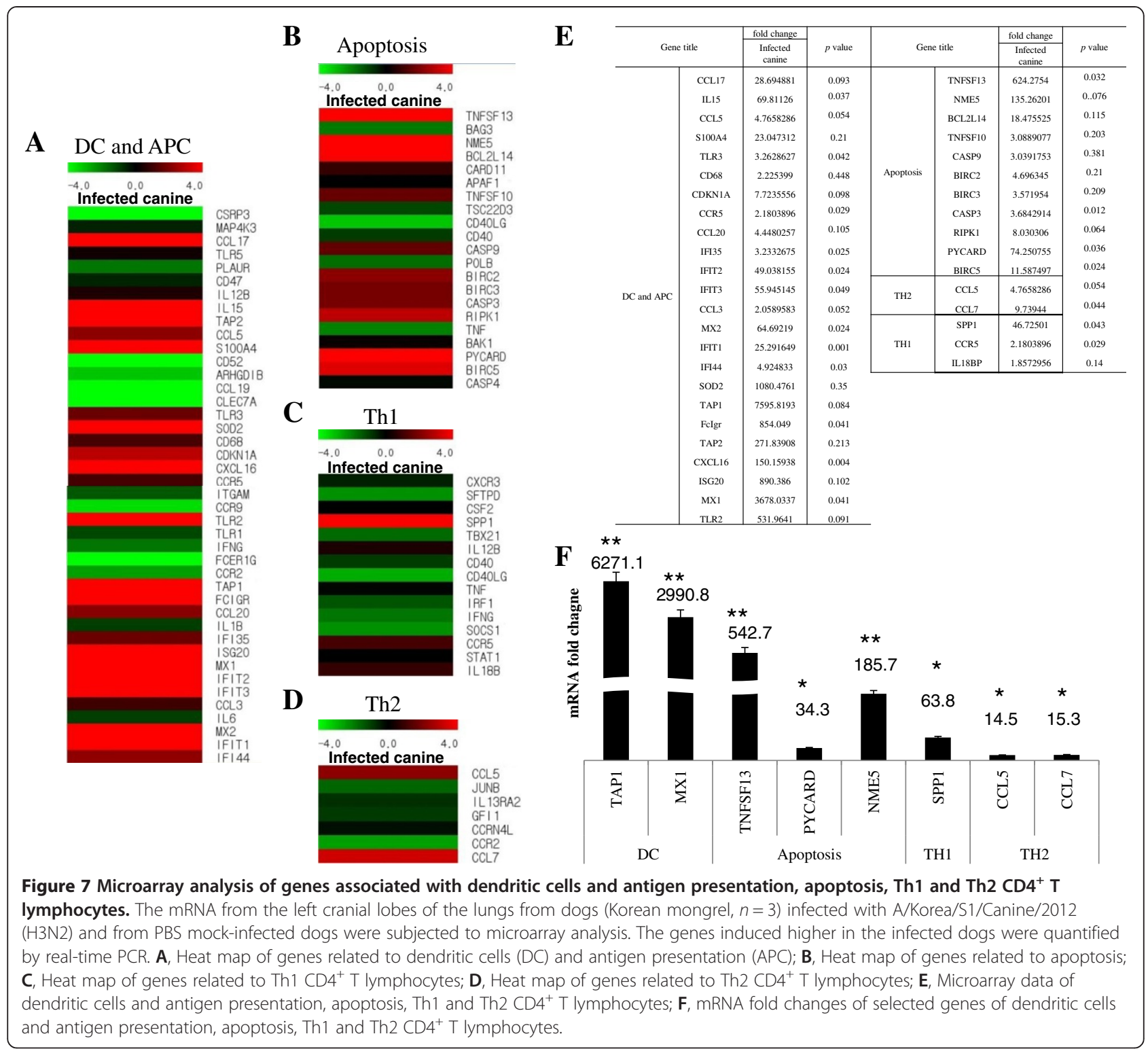

and did not cause severe clinical signs such as death in the transmitted ferret [30]. Another study on the aerosol transmission of avian origin H5N1 influenza virus suggested that the subsequent serial passages of an $\mathrm{H} 5 \mathrm{~N} 1$ influenza virus in ferrets could result in airborne transmission among ferrets. These transmissible H5N1 viruses contained four amino acid substitutions in the receptor-binding amino acids of $\mathrm{HA}$, and one in the polymerase complex protein basic polymerase 2 [31]. The transmission study in the ferrets carrying avian origin $\mathrm{H} 9 \mathrm{~N} 2$ influenza virus, which is a potential threat to humans, showed that the H9N2 influenza virus could be transmitted by direct contact with the ferrets, but it could not be transmitted to naïve ferrets via aerosols [32]. The swine-originated, pandemic H1N1 influenza virus of 2009 was easily transmissible among ferrets
$[33,34]$. When the ferrets were infected with the pandemic H1N1 influenza virus or the seasonal H1N1 influenza virus, both viruses were found to be efficiently transmissible among ferrets via aerosols [34]. In addition, the 2009 pandemic H1N1 influenza virus was transmitted among ferrets via contact and respiratory droplet exposure, before the earliest clinical sign of fever was detected [34].

Extensive transcriptional genomic analysis revealed that genes related to innate and adaptive immunity, inflammation, and apoptosis were highly active in the lungs of the dogs infected with canine H3N2 influenza virus, more than the lungs of PBS mock-infected dogs. The resulting immune responses of the dogs may also be responsible for contributing to the pathogenicity of the virus. Previous global transcriptional analysis studies also 


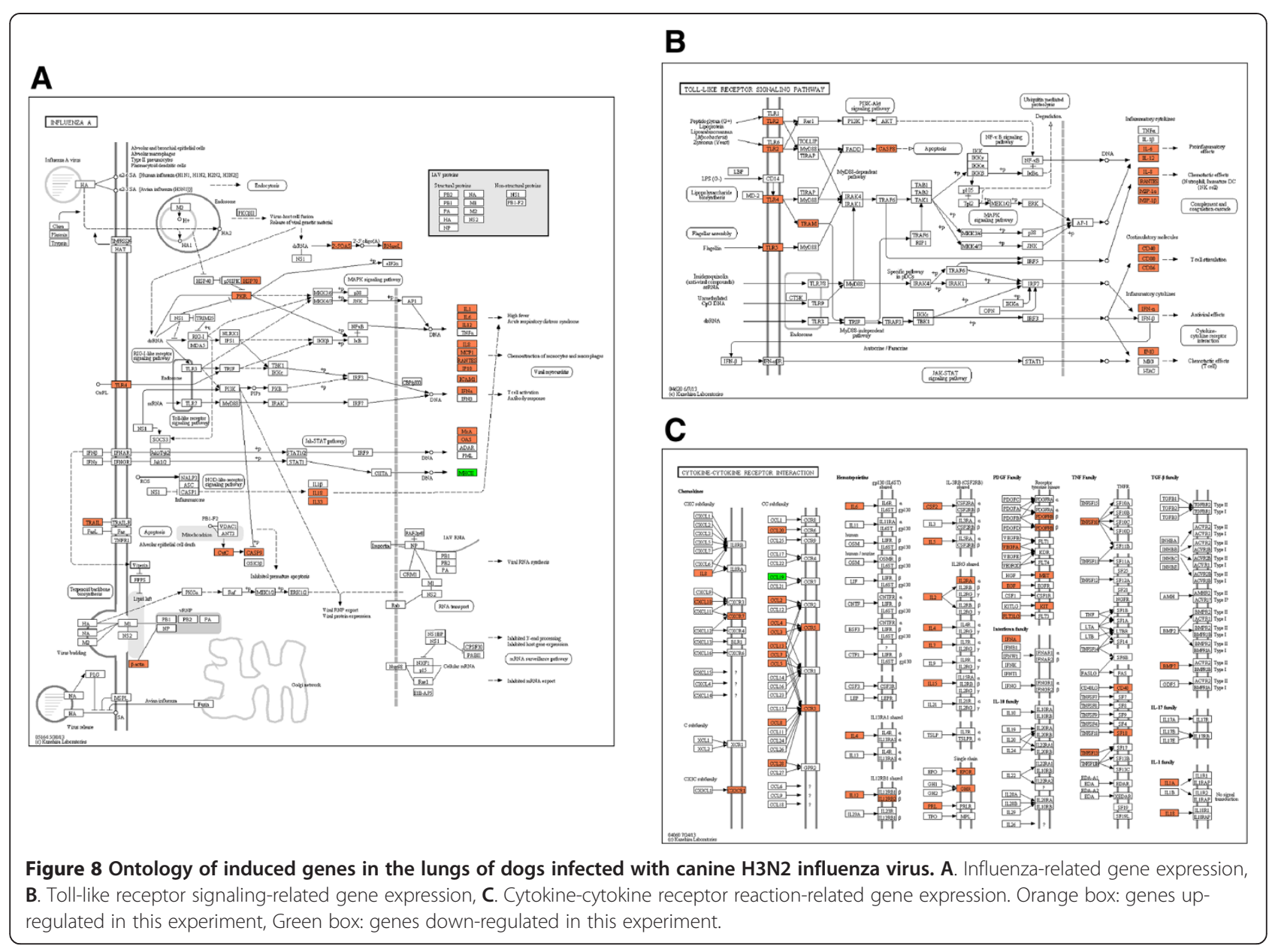

attributed the immune responses, including inflammation and apoptosis, to the enhanced pathogenicity of influenza viruses in animals [35-37]. A global transcriptional analysis was performed in macaques infected with the 1918 pandemic $\mathrm{H} 1 \mathrm{~N} 1$ or the avian origin H5N1 influenza virus [35]. Specific groups of genes related to inflammation and cell death were elevated in the bronchial tissues of macaques infected with the 1918 pandemic H1N1 influenza virus, but were downregulated by the avian origin $\mathrm{H} 5 \mathrm{~N} 1$ influenza virus [35]. When mice were infected with the 1918 pandemic H1N1 influenza virus, the genes associated with pro-inflammatory and cell death pathways were seen to be upregulated $24 \mathrm{~h}$ after infection, and remained so until death at 5 days [36]. Extensive transcriptional genomic profiles in the lungs of the ferrets showed that the interferon-response genes were more highly expressed in the avian origin H5N1infected ferret lungs than in the lungs of the ferrets infected with the H3N2 influenza virus, and strong CXCL10 gene expression was induced in the lungs of the ferrets infected with the avian origin H5N1 influenza virus [37].
Our data show that the gene expression in the lungs of dogs infected with canine H3N2 influenza virus was a little different between data of microarray and qPCR even though the overall patterns are related. The discrepancy between both methods may be due to the inherent pitfall of both methods that may influence the data obtained from each method as described in the previous studies [38-40].

In conclusion, our data suggest that the canine H3N2 influenza virus may be well adapted to infecting dogs, and that the pathogenesis of dogs infected with the canine H3N2 influenza virus may be due to the elevated expression of genes associated with immune responses and cell death in the lungs.

\section{Competing interests}

The authors declare that they have no competing interests.

\section{Authors' contributions}

YMK and HMK carried out the experiments on clinical observation, measurement of viral titers, tissue staining and microarray, and drafted the manuscript. KBK, EHP, and JY helped with the animal experiments. SHS conceived the study, and participated in its design and coordination. All authors read and approved the final manuscript. 


\section{Acknowledgments}

This research was in part supported by Basic Science Research Program through the National Research Foundation of Korea (NRF) funded by the Ministry of Education, Science and Technology (2012R1A2A2A01002533). A staff in Editage edited this manuscript.

Received: 25 February 2013 Accepted: 25 September 2013 Published: 3 October 2013

\section{References}

1. Bouvier NM, Palese P: The biology of influenza viruses. Vaccine 2008,26 (Suppl 4):D49-D53.

2. Webster RG, Bean WJ, Gorman OT, Chambers TM, Kawaoka Y: Evolution and ecology of influenza A viruses. Microbiol Rev 1992, 56:152-179.

3. Fouchier RA, Munster V, Wallensten A, Bestebroer TM, Herfst S, Smith D, Rimmelzwaan GF, Olsen B, Osterhaus AD: Characterization of a novel influenza A virus hemagglutinin subtype $(\mathrm{H} 16)$ obtained from blackheaded gulls. J Virol 2005, 79:2814-2822.

4. Johnson NP, Mueller J: Updating the accounts: global mortality of the 1918-1920 "Spanish" influenza pandemic. Bull Hist Med 2002, 76:105-115.

5. Reid AH, Fanning TG, Hultin JV, Taubenberger JK: Origin and evolution of the 1918 "Spanish" influenza virus hemagglutinin gene. Proc Natl Acad Sci U S A 1999, 96:1651-1656.

6. Taubenberger JK, Reid AH, Krafft AE, Bijwaard KE, Fanning TG: Initial genetic characterization of the "Spanish" influenza virus. Science 1997, 275:1793-1796.

7. Reid AH, Fanning TG, Janczewski TA, Taubenberger JK: Characterization of the 1918 "Spanish" influenza virus neuraminidase gene. Proc Natl Acad Sci USA 2000, 97:6785-6790.

8. Kawaoka Y, Krauss S, Webster RG: Avian-to-human transmission of the PB1 gene of influenza A viruses in the 1957 and 1968 pandemics. J Virol 1989, 63:4603-4608.

9. Scholtissek C, Rohde W, Von Hoyningen V, Rott R: On the origin of the human influenza virus subtypes H2N2 and H3N2. Virology 1978, 87:13-20.

10. Garten RJ, Davis CT, Russell CA, Shu B, Lindstrom S, Balish A, Sessions WM, Xu X, Skepner E, Deyde V, Okomo-Adhiambo M, Gubareva L, Barnes J, Smith CB, Emery SL, Hillman MJ, Rivailler P, Smagala J, De-Graaf M, Burke DF, Fouchier RA, Pappas C, Alpuche-Aranda CM, López-Gatell H, Olivera H, López I, Myers CA, Faix D, Blair PJ, Yu C, et al: Antigenic and genetic characteristics of swine-origin, $\mathrm{A}(\mathrm{H} 1 \mathrm{~N} 1)$ influenza viruses circulating in humans. Science 2009, 325:197-201

11. Crawford PC, Dubovi EJ, Castleman WL, Stephenson I, Gibbs EP, Chen L, Smith C, Hill RC, Ferro P, Pompey J, Bright RA, Medina MJ, Johnson CM, Olsen CW, Cox NJ, Klimov Al, Katz JM, Donis RO: Transmission of equine influenza virus to dogs. Science 2005, 310:482-485.

12. Songserm T, Amonsin A, Jam-on R, Sae-Heng N, Pariyothorn N, Payungporn S, Theamboonlers A, Chutinimitkul S, Thanawongnuwech R, Poovorawan Y: Fatal avian influenza A H5N1 in a dog. Emerg Infect Dis 2006, 12:1744-1747.

13. Song D, Kang B, Lee C, Jung K, Ha G, Kang D, Park S, Park B, Oh J: Transmission of avian influenza virus (H3N2) to dogs. Emerg Infect Dis 2008, 14:741-746.

14. Payungporn S, Crawford PC, Kouo TS, Chen LM, Pompey J, Castleman WL, Dubovi EJ, Katz JM, Donis RO: Influenza A virus (H3N8) in dogs with respiratory disease, Florida. Emerg Infect Dis 2008, 14:902-908.

15. Yoon KJ, Cooper VL, Schwartz KJ, Harmon KM, Kim WI, Janke BH, Strohbehn J, Butts D, Troutman J: Influenza virus infection in racing greyhounds. Emerg Infect Dis 2005, 11:1974-1976.

16. Butler D: Thai dogs carry bird-flu virus, but will they spread it? Nature 2006, 439:773.

17. Giese M, Harder TC, Teifke JP, Klopfleisch R, Breithaupt A, Mettenleiter TC, Vahlenkamp TW: Experimental infection and natural contact exposure of dogs with avian influenza virus (H5N1). Emerg Infect Dis 2008, 14:308-310.

18. Maas R, Tacken M, Ruuls L, Koch G, Van-Rooij E, Stockhofe-Zurwieden N: Avian influenza (H5N1) susceptibility and receptors in dogs. Emerg Infect Dis 2007, 13:1219-1221.

19. Li S, Shi Z, Jiao P, Zhang G, Zhong Z, Tian W, Long LP, Cai Z, Zhu X, Liao M, Wan XF: Avian-origin H3N2 canine influenza A viruses in Southern China. Infect Genet Evol 2010, 10:1286-1288.

20. Reed LE, Muench $\mathrm{H}$ : A simple method for estimating fifty percent endpoints. Am J Hyg 1938, 27:493-497.
21. Lowen AC, Mubareka S, Tumpey TM, García-Sastre A, Palese P: The guinea pig as a transmission model for human influenza viruses. Proc Natl Acad Sci U S A 2006, 103:9988-9992.

22. Bancrof JD, Stevens A: Theory and Practice of Histological Techniques. $4^{\text {th }}$ edition. New York: Churchill Livingstone; 1996.

23. Gao R, Dong L, Dong J, Wen L, Zhang Y, Yu H, Feng Z, Chen M, Tan Y, Mo Z, Liu H, Fan Y, Li K, Li CK, Li D, Yang W, Shu Y: A systematic molecular pathology study of a laboratory confirmed H5N1 human case. PLoS One 2010, 5:e13315.

24. Cameron CM, Cameron MJ, Bermejo-Martin JF, Ran L, Xu L, Turner PV, Ran R, Danesh A, Fang Y, Chan PK, Mytle N, Sullivan TJ, Collins TL, Johnson MG, Medina JC, Rowe T, Kelvin DJ: Gene expression analysis of host innate immune responses during Lethal H5N1 infection in ferrets. J Virol 2008, 82:11308-11317

25. Gene Ontology Database [http://www.geneontology.org/].

26. BioCarta [http://www.biocarta.com/].

27. Gene Map Annotator and Pathway Profiler [http://www.genmapp.org/]

28. DAVID Bioinformatics Resources 6.7. [http://david.abcc.ncifcrf.gov/].

29. National Center for Biotechnology Information [http://www.ncbi.nlm.nih.gov/]

30. Imai M, Watanabe T, Hatta M, Das SC, Ozawa M, Shinya K, Zhong G, Hanson A, Katsura H, Watanabe S, Li C, Kawakami E, Yamada S, Kiso M, Suzuki Y, Maher EA, Neumann G, Kawaoka Y: Experimental adaptation of an influenza $\mathrm{H} 5 \mathrm{HA}$ confers respiratory droplet transmission to a reassortant H5 HA/H1N1 virus in ferrets. Nature 2012, 486:420-428.

31. Herfst S, Schrauwen EJ, Linster M, Chutinimitkul S, De-Wit E, Munster VJ, Sorrell EM, Bestebroer TM, Burke DF, Smith DJ, Rimmelzwaan GF, Osterhaus $A D$, Fouchier RA: Airborne transmission of influenza $A / H 5 N 1$ virus between ferrets. Science 2012, 336:1534-1541.

32. Wan H, Sorrell EM, Song H, Hossain MJ, Ramirez-Nieto G, Monne I, Stevens J, Cattoli G, Capua I, Chen LM, Donis RO, Busch J, Paulson JC, Brockwell C, Webby R, Blanco J, Al-Natour MQ, Perez DR: Replication and transmission of H9N2 influenza viruses in ferrets: evaluation of pandemic potential. PLoS One 2008, 3:e2923.

33. Roberts KL, Shelton H, Stilwell P, Barclay WS: Transmission of a $2009 \mathrm{H} 1 \mathrm{~N}$ pandemic influenza virus occurs before fever is detected, in the ferret model. PloS One 2012, 7:e43303.

34. Munster VJ, De-Wit E, van den-Brand JM, Herfst S, Schrauwen EJ, Bestebroer TM, van de-Vijver D, Boucher CA, Koopmans M, Rimmelzwaan GF, Kuiken T, Osterhaus AD, Fouchier RA: Pathogenesis transmission of swine-origin, $A(H 1 N 1)$ influenza virus in ferrets. Science 2009, 2009(325):481-483.

35. Cillóniz C, Shinya K, Peng X, Korth MJ, Proll SC, Aicher LD, Carter VS, Chang JH, Kobasa D, Feldmann F, Strong JE, Feldmann H, Kawaoka Y, Katze MG: Lethal influenza virus infection in macaques is associated with early dysregulation of inflammatory related genes. PLoS Pathog 2009, 5:e1000604.

36. Kash JC, Tumpey TM, Proll SC, Carter V, Perwitasari O, Thomas MJ, Basler CF, Palese P, Taubenberger JK, García-Sastre A, Swayne DE, Katze MG: Genomic analysis of increased host immune and cell death responses induced by 1918 influenza virus. Nature 2006, 443:578-581.

37. Song BM, Kang YM, Kim HS, Seo SH: Induction of inflammatory cytokines and toll-like receptors in human normal respiratory epithelial cells infected with seasonal H1N1, 2009 pandemic H1N1, seasonal H3N2, and highly pathogenic H5N1 influenza virus. Viral Immunol 2011, 24:179-187.

38. Bustin SA: Quantification of mRNA using real-time reverse transcription PCR (RT-PCR): trends and problems. J Mol Endocrinol 2002, 29:23-39.

39. Chuaqui RF, Bonner RF, Best CJ, Gillespie JW, Flaig MJ, Hewitt SM, Phillips JL, Krizman DB, Tangrea MA, Ahram M, Linehan WM, Knezevic V, Emmert-Buck MR: Post-analysis follow-up and validation of microarray experiments. Nat Genet 2002, 32:509-514.

40. Yang YH, Dudoit S, Luu P, Lin DM, Peng V, Ngai J, Speed TP: Normalization for CDNA microarray data: a robust composite method addressing single and multiple slide systematic variation. Nucleic Acids Res 2002, 30:e15.

doi:10.1186/1297-9716-44-92

Cite this article as: Kang et al: H3N2 canine influenza virus causes severe morbidity in dogs with induction of genes related to inflammation and apoptosis. Veterinary Research 2013 44:92. 